\title{
Systemic sclerosis in Iceland. A nationwide epidemiological study
}

\author{
Árni Jón Geirsson, Kristián Steinsson, Sveinn Guð̄mundsson, Vigfús Sigurð̄sson
}

\begin{abstract}
Objectives-To investigate the incidence, prevalence and clinical features of systemic sclerosis (SS) in Iceland.

Methods-All patients diagnosed with SS from 1975-90 were included. Retrieval for the study began in 1980 and was carried out by computerised search from registers of all hospitals and health care clinics and death registration files, and with personal communication with doctors in Iceland Results-Over a 16 year period from 1975-90, 15 new cases were found with an incidence of 0.7 and $0.05 / 100000$, for females and males at risk respectively, and 0.38 for both sexes. At the end of 1990 there were 18 patients alive with SS, 13 with limited and five with diffuse cutaneous involvement. The age standardised prevalence was 11.9 and $1 \cdot 5 / 100000$ for females and males at risk respectively. The crude prevalence rate for both sexes was $7 \cdot 1 / 100000$. There were five deaths, two patients died of SS related causes, one had SS renal disease. The relative risk of death was similar to that in the general population. The calculated five year survival rate was $100 \%$ and the 10 year survival rate $81 \%$. No HLA antigen association was found.

Conclusion-Compared with previous surveys this study shows a low incidence of systemic sclerosis and a high proportion of patients with limited cutaneous involvement.
\end{abstract}

(Ann Rheum Dis 1994; 53: 502-505)

Systemic sclerosis (scleroderma) is a rare disease affecting skin and internal organs. The aetiology is largely unknown, the role of genetic factors is unclear, but environmental factors, such as, polyvinyl chloride, silica and coal are thought to be of importance in inducing symptoms and to have implications in the progression of the disease. ${ }^{1}$ Systemic sclerosis (SS) has been considered to run a progressive course with a rather bleak prognosis. Of importance is that virtually all the descriptive epidemiology of SS is derived from studies on selected patient materials. Such studies tend to overestimate the gravity of diseases such as SS. ${ }^{2}$ In the present study the 1980 ARA criteria were applied for the classification of SS in an unselected population. The structure of the study allows us to conclude that we have probably screened the whole population for SS. It is of interest to study a disease such as SS in an ethnically homogeneous community like Iceland where potentially noxious environmental factors are minimal compared with highly industrialised countries.

\section{Materials and methods}

The Icelandic population (255708 on 1 December 1990) is homogeneous with ethnic origin from the Nordic countries and Ireland. The health care system in Iceland is community-based and medical service is readily available; the small size of the country facilitates easy flow of information. ${ }^{3}$ Retrieval for the study began in 1980 and was ongoing during the study period. It was carried out by a computer search in the registers of all hospitals and health care centres in Iceland, at health care centres without computorised registration a personal contact was made with the local doctors, to look for patients with the diagnosis of systemic sclerosis. A questionnaire asking for that diagnosis was sent to: district medical doctors, private practitioners, internists, neurologists, paediatricians, dermatologists, nephrologists, and rheumatologists as well as other physicians likely to have information on patients who had never been admitted to hospitals with this diagnosis. Death registration and necropsy reports for suspected cases were also checked. The diagnosis was made in hospital in $78 \%$ of the cases and the remainder was diagnosed outside hospitals. In this way we believe we screened the whole population for sytemic sclerosis. The records of all patients registered with this diagnosis from 1 January 1975 through 31 December 1990 were reviewed and the 18 patients alive with this diagnosis called for examination. Patients with overlap features of lupus, scleroderma and polymyositis and the solitary presence of high titre anti-RNP antibodies were considered mixed connective tissue disease cases and not included in the study.

The 1980 ARA criteria used for the classification of systemic sclerosis were applied. ${ }^{4}$ Patients were classified as having limited systemic sclerosis or CREST syndrome (calcinosis, Raynaud's phenomenon, oesophageal dysmotility, sclerodactyly, telangiectasias) if truncal scleroderma was absent and, classified as having diffuse systemic sclerosis if truncal scleroderma was present. A predefined protocol was used to fulfill clinical and laboratory 
parameters serially for every patient. Patients with a localised form of scleroderma, that is, linear scleroderma or scleroderma morphea, were not included in the study.

The annual incidence of systemic scleroderma was calculated from the number of patients first registered as having systemic sclerosis during the 16 year period. The prevalence of systemic sclerosis was calculated from the number of patients alive on 31 December 1990. Incidence and prevalence rates were standardised to the world population as defined by Segi. ${ }^{5}$ Survival rates were calculated by the Kaplan Meyer life table method from the year of diagnosis until 31 December 1990.

An overall clinical assessment, including skin score, laboratory profile and urinalysis was performed three times annually from 1988-90 for each of the 18 patients alive with the disease.

HLA-typing for class I antigens was done on 20 patients and 333 controls, and class II antigens were tested on 17 patients and 50 controls, with the methods of Vartal et al. ${ }^{6}$ Statistical analysis was carried out with a Chi square contingency table. ${ }^{7}$

Antinuclear antibody (ANA) was detected by a standardised immunofluorescence technique, using a rat liver as a substrate. ${ }^{8} \mathrm{~A}$ positive ANA was defined as a titre of more than $1 / 20$, where $95 \%$ of the normal population had a titre of $1 / 20$ or less. An ELISA technique was used to detect antibodies against the Scl-70 and SSA nuclear elements. ${ }^{9}$ Cellular ELISA was used to detect antibodies against endothelial cells. ${ }^{10}$ Anti-centromere antibody testing was carried out on prepared mitotic cells from Immuno Concepts California by immunofluorescence technique. ${ }^{11}$

\section{Results}

The response rate to the questionnare was over $95 \%$. In the 16 year period there were 15 new cases, 14 females and one male classified as systemic sclerosis. The mean age at the time of diagnosis was 43.8 years (range $5-70$ ). The age specific annual incidence rates are shown in table 1 . The crude rate for both sexes was $0 \cdot 38 / 100000 /$ year, the age standardised annual incidence rate was 0.7 for women and 0.05 for men respectively. At the end of 1990 there were 18 patients alive, 16 women and 2 men, with a total crude prevalence rate of $7 \cdot 1 / 100000$. The age standardised prevalence rate was 11.9 for women and $1.5 / 100000$ for men. For the 18 patients alive at the end of 1990 the mean disease duration from onset of subjective feeling of skin swelling and thickening on the fingers, was 9.9 years (range 1-27), the mean age was 53.5 years (range 15-85). Clinical features of the 18 patients alive at the end of 1990 are shown in table 2 . Thirteen were classified as having limited and five as having diffuse systemic sclerosis. Clinically relevant kidney disease as shown by increased serum creatinine, hypertension, formed elements in the urine, significant proteinuria or haematuria was not found in any of the 18 patients on close follow up over three
Table 1 Annual age specific incidence rates of systemic sclerosis in Iceland from 1975-90

\begin{tabular}{|c|c|c|c|c|}
\hline \multirow[t]{2}{*}{ Age groups } & \multicolumn{2}{|c|}{ Females } & \multicolumn{2}{|c|}{ Males } \\
\hline & $N o^{\star}$ & Rate ${ }^{\star \star}$ & $N o^{\star}$ & Rate $^{\star \star}$ \\
\hline $0-9$ & 1 & 1 & 0 & 0 \\
\hline $10-19$ & 0 & 0 & 0 & 0 \\
\hline $20-29$ & 2 & 2 & 0 & 0 \\
\hline $30-39$ & 2 & 2 & 0 & 0 \\
\hline $40-49$ & 4 & 4 & 1 & 1 \\
\hline $50-59$ & 3 & 3 & 0 & 0 \\
\hline $60-69$ & 1 & 1 & 0 & 0 \\
\hline $70-79$ & 1 & 2 & 0 & 0 \\
\hline $80+$ & 0 & 0 & 0 & 0 \\
\hline $\begin{array}{l}\text { Overall age } \\
\text { Standardised rate }\end{array}$ & & 0.7 & & 0.05 \\
\hline
\end{tabular}

*Total number of new systemic sclerosis cases in a 16 year period.

$\star \star$ Rates per 100000 population risk per year.

$\dagger$ Standardised to the world population.

years (1988-91) or in the patients' previous records. Positive ANA was found in 15 patients, anti-nucleolar pattern was found in 11 patients, antibodies against Scl 70 in four and against SSA in three. Antibodies against endothelial cells were found in six patients. Anti-centromere antibodies were found in two patients with limited SS and in no patient with diffuse SS. Autoantibody profiles are shown in table 3 .

Testing for class I and II HLA antigens revealed no significant association (table 4)

Mean values for haemoglobin, sedimentation rate, serum creatinine and CRP were within normal limits for the group as a whole.

There were five deaths during the study period, three males and two females. The mean (SD) age at death was $66(13 \cdot 8)$ years range 53-85). The expected number of deaths according to mortality in the general population and age and sex distribution of the study group was 1.2 for women and one for men; thus the risk ratio is 1.7 (95\% confidence interval $0 \cdot 2-6 \cdot 1)$, and 3.0 (95\% confidence interval $0 \cdot 6-8 \cdot 8$ ) respectively. The calculated five year survival rate was $100 \%$ and the 10 year survival rate $81 \%$. The mean disease duration at the time of death was 12.5 years. One of five patients who died had diffuse SS, the other four had limited SS. One of the five patients had evidence of renal involvement with increased creatinin and abnormal urinalysis at the time of death. Three of the patients died from cardiovascular causes, one from cancer, and one from unknown causes. In two cases the deaths could be related directly to systemic sclerosis, one of the two had SS renal disease and the other SS cardiac disease.

\section{Discussion}

In our nationwide survey the 1980 ARA criteria were applied for the classification of systemic sclerosis. The structure of the study allows us to conclude that we probably screened the whole population for systemic sclerosis. The under-ascertainment was thought to be minimal since retrieval for the study has been ongoing since 1980 . Published reports show a variable incidence of systemic sclerosis; the incidence in Iceland of 3.8 per million is in the lower range. ${ }^{2}$ Recent data from 
Table 2 Organ involvement in 18 patients with systemic sclerosis

\begin{tabular}{|c|c|c|c|c|}
\hline & \multicolumn{2}{|c|}{ Diffuse SS (no 5) } & \multicolumn{2}{|c|}{ Limited SS (no 13) } \\
\hline & No & $\%$ & No & $\%$ \\
\hline Peripheral vascular (Raynaud's phenomenon) & 5 & $(100)$ & 12 & $(92)$ \\
\hline Arthritis/tenosynovitis & 3 & $(60)$ & 12 & (92) \\
\hline Gastrointestinal & 4 & $(80)$ & 10 & (77) \\
\hline Cardiac & 3 & $(60)$ & 6 & (46) \\
\hline Pulmonary & 5 & $(100)$ & 8 & $(62)$ \\
\hline Renal & 0 & & 0 & \\
\hline Mucosal membranes (Sjögren's s.) & 0 & & 4 & $(31)$ \\
\hline
\end{tabular}

Table 3 Autoantibodies in 18 patients with systemic sclerosis

\begin{tabular}{lrl}
\hline & $N o$ & $\%$ \\
\hline ANA & 15 & $(83)$ \\
Anti-Scl 70 & 4 & $(22)$ \\
Anti-nucleolar & 11 & $(61)$ \\
SS A & 3 & $(17)$ \\
Anti-endothelial & 6 & $(33)$ \\
Anti-centromere & 2 & $(11)$ \\
\hline
\end{tabular}

Table 4 HLA-association with systemic sclerosis in Iceland

\begin{tabular}{|c|c|c|c|c|c|c|c|}
\hline \multirow[t]{2}{*}{ Antigen } & \multicolumn{2}{|c|}{ Patients } & \multicolumn{2}{|c|}{ Controls } & \multirow[t]{2}{*}{$R R$} & \multirow[t]{2}{*}{$X 2$} & \multirow{2}{*}{$\begin{array}{l}P \text { (correction for number } \\
\text { of antigens by Bonferoni } \\
\text { inequality method) }\end{array}$} \\
\hline & $h$ & $k$ & $H$ & $K$ & & & \\
\hline Al & 7 & 13 & 120 & 213 & 0.984 & 0.209 & NS \\
\hline A1 1 & 6 & 14 & 65 & 268 & 1.838 & 1.627 & NS \\
\hline B5 & 2 & 18 & 6 & 327 & 6.809 & 1.627 & NS \\
\hline B8 & 7 & 13 & 51 & 282 & 3.047 & 5.666 & NS \\
\hline B15 & 1 & 19 & 66 & 267 & 0.309 & $2 \cdot 417$ & NS \\
\hline B18 & 3 & 17 & 21 & 312 & 2.907 & 3.216 & NS \\
\hline DR1 & 6 & 11 & 6 & 44 & 3.870 & $4 \cdot 683$ & NS \\
\hline DR4 & 3 & 14 & 19 & 31 & 3.900 & $2 \cdot 230$ & NS \\
\hline DR5 & 3 & 14 & 3 & 47 & $3 \cdot 276$ & $2 \cdot 397$ & NS \\
\hline DR8 & 4 & 13 & 3 & 47 & $4 \cdot 524$ & 4.201 & NS \\
\hline
\end{tabular}

$\mathrm{h}=$ patients positive for the antigen, $\mathrm{k}=$ patients negative for the antigen, $\mathrm{H}=$ controls positive for the antigen, $K=$ controls negative for the antigen, $R R=$ relative risk.

$\mathrm{X} 2=$ statistical significance of the difference from $\mathrm{RR}$.

$\mathrm{P}=$ probability corrected for the number of antigens by Bonferoni inequality method.

NS $=$ Not significant hypertension and decreased glomerular filtration. The good prognosis in Icelandic patients may in part be explained by the fact that, for some reason, they seem to have less renal involvement even though involvement of other internal organs is as common as elsewhere. The unselected nature of our study might partly be the reason for the relatively high proportion of mild cases, which was also noted for patients with lupus in Iceland, where there was low incidence of renal involvement. ${ }^{3}$ The renal protective factor is unknown; it could be on a genetic basis or due to the absence of noxious environmental factors. The patients diagnosed before 1984 were treated with a combination of hydralazine $25 \mathrm{mg}$ three times a day glutamine $200 \mathrm{mg}$ twice a day and penicillamine $500-750 \mathrm{mg}$ four times a day, according to Asboe-Hansen, ${ }^{17}{ }^{18}$ this was not carried out in a controlled fashion, but may have had a bearing on the outcome.

Systemic sclerosis is characterised by sclerosis of the skin, yet involvement of internal organs is predictive for survival. ${ }^{19}{ }^{20}$ Reduced survival rates in systemic sclerosis are most apparent during the first two years of the disease and tend to be related to older age, male sex, anaemia, a high sedimentation rate and evidence of renal, cardiac or pulmonary involvement. ${ }^{21} \mathrm{~A}$ low haemoglobin level in younger patients and impaired renal function in older patients are the best predictors of mortality. ${ }^{22}$ There have been a number of studies on survival in systemic sclerosis, all showing survival at five and 10 years to be $44-73 \%$ and $42-59 \%$ respectively. ${ }^{23} 31$ In Iceland the overall survival rate of patients with systemic sclerosis seems to be considerably higher where five year survival was found to be $100 \%$ and 10 year survival $81 \%$, this may be a reflection of the fact that most of the patients have limited cutaneous involvement that is considered to carry a better prognosis. The risk of death among patients with systemic sclerosis is similar to that of the general sex- and agematched Icelandic population. The small size of the study population, however, makes it hard to draw any conclusions regarding survival rates, but at least it can be said that systemic sclerosis in Iceland is a benign disease.

The association of systemic sclerosis with the HLA antigens has been weak. Numerous early reports suggested an association with $\mathrm{B} 8^{32}{ }^{33}$ but this has not been a universal finding. Later testing for class II antigens suggested an association with DR3 and DR. ${ }^{2}$ In our study we found no association with the HLA antigens. The patients came from all over Iceland and are not related, and are not of the 'rheuma' families in Iceland, nor was there any time clustering apparent.

In summary, our nationwide study of an unselected population, found systemic sclerosis to be rarer, and the prognosis better in Iceland than previously reported elsewhere. We thank Jon Thorsteinsson for valuable clinical information
and Inga Skaftadóttir for performing the HLA typing. We also and Inga Skaftadóttir for performing the HI.
thank Helgi Sigvaldason for statistical help.

Supported by the Icelandic Science Foundation.
Renal involvement is rare at diagnosis in systemic sclerosis but emerges in $45 \%$ of the patients on the average 3.2 years after diagnosis. ${ }^{16}$ This is shown by haematuria, proteinuria and abnormal urinary sediment, 
1 Silman A J. Epidemiology of scleroderma. Current opinion in Rheumatology 1991; 3: 967-72.

2 Silman A J. Epidemiology of scleroderma. Ann Rheum Dis 1991; 50: 846-53.

3 Gudmundsson S, Steinsson K. Systemic Lupus Erythematosus in Iceland 1975 Through 1984. A Nationwide Epidemiological Study in an Unselected Nationwide Epidemiological Study in an Uns
Population. F Rheumatology 1990; 17:9: 1162-7

4 Masi A T, Rodnan G P, Medsger T A jr, et al. Preliminary criteria for the classification of systemic sclerosis (scleroderma). Arthritis Rheum 1980; 23: 581-90.

5 Segi M. Cancer Mortality for Selected Sites in 24 Countries (1950-1957). Sendai: Tohoku University School of Medicine, 1960.

6 Vartdal F, Gaudernack G, Funderud S, et al. HLA Class I and II typing using cells positively selected from blood by immunomagnetic isolation-a fast and reliable technique. Tissue Antigens 1986; 28: 41-5.

7 Tiwari J L, Tersaski P I. HLA and disease associations. New York: Springer Verlag, 1985.

8 Coons A. A Fluorescent antibody methods. Gen Cytochem Methods 1958; 1: 399-422.

9 Hudson I, Hay, F C. Practical immunology. Oxford: Blackwell Scientific, 1980: 237

10 Hashemi S, Smith D, Izaguirre C A. Anti-endothelial cell antibodies: Detection and characterization using a cellular enzyme-linked immunosorbent assay. $7 \mathrm{Lab}$ Clin $\mathrm{Med}$ 1987; 109: 434-40.

11 Tan E M, Rodnan G P, Garcia I, et al. Diversity of antinuclear antibodies in progressive systemic sclerosis. Antinuclear antibodies in progress

12 Steen V, Conte C, Santoro D, et al. Twenty year incidence survey of systemic sclerosis (abstract). Arthritis Rheum 1988; 31 (suppl 14): 557.

13 Maricq H R, Weinrich M C, Keil J E, et al. Prevalence of scleroderma spectrum disorders in the general population of South Carolina. Arthritis Rheum 1989; 32: 998-1006.

14 Erasmus L D. Scleroderma in coal miners on the Witwatersrand with particular reference to pulmonary manifestation. S Afr $\mathcal{f}$ Lab Clin Med 1957; 3: 209-3i.

15 Black C M, Walker A E, Cattogio L J, et al. Genetic susceptibility to scleroderma-like syndrome induced by vinyl chloride. Lancet 1983; 1/8: 53-55.

16 Rocco V K, Hurd E R. Scleroderma and scleroderma-like disorders. Semin Arthritis Rheum 1986; 16: 22-69.
17 Asboe-Hansen G. The treatment of generalized scleroderma with inhibitors of connective tissue formation. Acta Dermatovener 1975; 55: 461-65.

18 Asboe-Hansen G. Treatment of generalized scleroderma: Updated results. Acta Dermatovener 1979; 59: 465-67.

19 Le Roy E C. The heart in systemic sclerosis. N Engl f Med 1984; 310: $188-9$.

20 Medsger T A jr, Masi A T. Epidemiology of systemic sclerosis (scleroderma). Ann Int Med 1971; 74: 714-21.

21 Medsger T A jr, Masi A T. Epidemiology of progressive systemic sclerosis. Clin Rheum Dis 1979; 5: 15-25.

22 Altman R D, Medsger T A, Bloch D A, Michel B A. Predictors of survival in systemic sclerosis (scleroderma). Arthritis Rheum 1991; 34: 403-13.

23 Tuffanelli D L, Winkelman R K. Systemic scleroderma: clinical study of 727 cases. Arch Dermatol 1961; 84: 359-71.

24 Bennett R, Bluestone R, Holt P J L, et al. Survival in scleroderma. Ann Rheum Dis 1971; 30: 581-88.

25 Rowell N R. The prognosis of systemic sclerosis. $\mathrm{Br} f$ Dermatol 1976; 95: 57-60.

26 Farmer R G, Gifford R W, Hines E A. Prognostic significance of Raynaud's phenomenon and other clinical characteristics of systemic scleroderma. Circulation 1960; 21: 1088-95.

27 Medsger T A, Rodnan G P, Robinson H. Survival with systemic sclerosis (scleroderma). A life table analysis of clinical and demographic factors in 309 patients. Ann Intern Med 1971; 75: 369-76.

28 Medsger T A, Masi A T. Survival with scleroderma II: A life-table analysis of clinical and demographic factors in 358 male US veterans patients. F Chronic Dis 1973; 26: $358 \mathrm{mal}$
$647-60$.

29 Barnett A J. Scleroderma (progressive systemic sclerosis): Progress and course based on personal series of 118 cases. Med F Aust 1978; 2: 129-34.

30 Wynn J, Fineberg N, Metzes L, et al. Prediction of survival in progressive systemic sclerosis by multivariate analysis of clinical features. Am Heart f 1985; 110: 123-27.

31 Bulpitt K, Clements P, Lachanbruch P, et al. Prospective study of early systemic sclerosis: outcome and prognostic indicators. Arthritis Rheuma 1990; 33 (suppl): R6

32 Rabin B S, Rodnan G P, Bassion S, et al. HLA antigens in progressive systemic sclerosis (scleroderma). Arthritis progressive systemic sclero

33 Huges R, Gelsthorp K, Doughty R W, et al. The association of HLA-B8 with visceral disease in systemic sclerosis. Clin Exp Immunol 1978; 31: 351-56. 